\title{
CIDADE, TRABALHO E HABITAÇÃO: OBSERVAÇÕES INICIAIS SOBRE A QUALIDADE HABITACIONAL
}

\author{
Sônia Dique Fragozo ${ }^{1}$ \\ Bruno Borges Mamede ${ }^{2}$ \\ Luis Otávio Cocito de Araújo ${ }^{3}$
}

\begin{abstract}
RESUMO
Este artigo materializa o início da pesquisa de mestrado da autora principal e pretende abordar a relação existente entre a produção das cidades a partir do trabalho e a localização das habitações destinadas à populações com menores níveis de renda. Estas estão segregadas das áreas urbanas com maior quantidade de infraestrutura e, desta maneira, ocupam bairros marginais e cada vez mais distantes destas áreas. Com as políticas recentes de urbanização de áreas com assentamentos precários, a melhoria das habitações comporia uma etapa complementar a busca de melhor qualidade de vida destes locais.
\end{abstract}

Palavras-Chave: Engenharia Urbana, Habitabilidade Urbana, Urbanismo Sustentável.

\section{CITY, WORK AND HOUSING: INITIAL OBSERVATIONS ON THE QUALITY HOUSING}

\begin{abstract}
This article materializes the begging of the main author's research for her master's degree and pretends to analyze the existent relationship between the production of cities from working/labor and the placement of habitations designated to population with lower levels of income. These ones are segregated from the areas with more urban infrastructure and, therefore, occupy marginal and even farther neighborhoods from those. Observing recent politics directed to precarious settlements urbanization, the habitation implement would compose a complementary step for the raising of local life quality.

\footnotetext{
1 Arquiteta e Urbanista (UFRJ), Aluna de Mestrado em PEU/POLI/UFRJ e Professora de Ensino Técnico e Tecnológico (FAETEC), sonia.fragozo@poli.ufrj.br.

${ }^{2}$ Comunicador Social (PUC-Rio) e Geógrafo (UERJ), Aluno de Mestrado em PEU/POLI/UFRJ e de Especialização em IPPUR/UFRJ, bruno.mamede@poli.ufrj.br.

${ }^{3}$ Doutor em Construção Civil (USP), Professor em PEU/POLI/UFRJ, luis.otavio@poli.ufri.br.
} 
Keywords: Urban Engineering, Urban Habitability, Sustainable Urbanism.

\section{CIUDAD DE TRABAJO Y VIVIENDA: OBSERVACIONES INICIALES SOBRE LA CALIDAD DE LA VIVIENDA}

\section{RESUMÉN}

Este artículo materializa el inicio de la investigación de maestría de la autora principal y busca abarcar la relación existente entre la producción de ciudades a partir del trabajo y la localización de las habitaciones destinadas a las poblaciones con los menores niveles de renda. Estas están segregadas de las áreas con mayor presencia de infraestructura urbana y, así, ocupan los barios marginales y cada vez más distantes de aquellas. Observando las políticas direccionadas a la urbanización de asentamientos precarios, la implementación de las habitaciones podría componer una etapa al aumento de la calidad de vida local.

Palabras-Clave: Ingeniería Urbana, Habitabilidad Urbana, Urbanización Sostenible.

\section{INTRODUÇÃO: PROPOSTA E OBJETIVO}

A percepção pelo interesse de pessoas de baixa renda implementar suas habitações emerge a partir de cursos de capacitação na área de construção civil, onde muitos alunos tem contato com técnicas e materiais de construção até então desconhecidos. A necessidade de sanar problemas resultantes da ausência de uma capacitação técnica mínima é geradora de inúmeras questões presentes nestes cursos.

O objetivo desse trabalho é demonstrar que a partir da melhoria das habitações existentes em assentamentos precários há um caminho viável, não só para a contribuição na diminuição do déficit habitacional, mas principalmente, para a melhoria das condições de vida dessa população.

Esta etapa do trabalho será desenvolvida a partir de consulta bibliográfica e alguns dados documentais. Para a delimitação das áreas de estudo serão utilizadas informações georreferenciadas do IBGE pertinentes ao município do Rio de Janeiro, tal como mencionado anteriormente. Não se pretende abordar conjuntos habitacionais destinados à população de baixa renda por entender que tais edificações não 
possuem características de autoconstrução existentes nos domicílios em assentamentos precários e, quando estas estão presentes, apresentam-se em situações muito específicas que fogem ao escopo deste trabalho.

Ao longo deste trabalho os assentamentos precários serão um conceito-chave para o desenvolvimento das análises aqui apresentadas. Para IBGE (2000), este é denominado como aglomerados subnormais, sendo sua definição e critérios:

Conjunto constituído de, no mínimo, 51 unidades habitacionais (barracos, casas...) carentes, em sua maioria de serviços públicos essenciais, ocupando ou tendo ocupado, até período recente, terreno de propriedade alheia (pública ou particular) e estando dispostas, em geral, de forma desordenada e densa. A identificação dos Aglomerados Subnormais é feita com base nos seguintes critérios:

a) Ocupação ilegal da terra, ou seja, construção em terrenos de propriedade alheia (pública ou particular) no momento atual ou em período recente (obtenção do título de propriedade do terreno há dez anos ou menos); e

b) Possuir pelo menos uma das seguintes características:

- urbanização fora dos padrões vigentes - refletido por vias de circulação estreitas e de alinhamento irregular, lotes de tamanhos e formas desiguais e construções não regularizadas por órgãos públicos;

- precariedade de serviços públicos essenciais.

(IBGE, 2010, p. 25)

Farias (2009) menciona que a localização destas populações em áreas com carência de infraestrutura, equipamentos e serviços urbanos adequados à população residente advém da segregação social. Neste ponto, Santos (2010) aprofunda a discussão ao mencionar que as elites ocupam os poderes locais e reproduzem em seus territórios a infraestrutura necessária para um bom nível de vida no ambiente urbano e, para a maior parte da população desprovida de recursos, sobram algumas poucas bem feitorias realizadas apenas em um determinado ponto do sistema urbano (pavimentação de ruas ou iluminação pública, por exemplo), criando desta forma área que constantemente necessitam de serviços e equipamentos adequados.

Cidades (2010) aponta que com as recentes políticas municipais e estaduais de implemento das condições de urbanização destes bairros, observa-se que não apenas da melhoria do entorno, mas também das próprias unidades habitacionais em algumas iniciativas simples permite melhoras significativas na qualidade de vida das famílias.

Com isto, a possibilidade de proporcionar melhores condições de habitabilidade em assentamentos precários existentes utilizando da mão de obra local num sistema 
de autoconstrução supervisionada é uma alternativa de baixo custo para a inserção de áreas degradadas à cidade. Em consonância as ideias de Araújo (2010), acreditase que esta iniciativa não só transforma as habitações subnormais, como seu entorno e seus moradores possibilitando maior qualidade de vida, em conjunto a melhores condições de saúde e cidadania.

\section{1- PRODUÇÃO DE CIDADES: TRABALHO E HABITAÇÃO}

Historicamente no Brasil, a tentativa de erradicação das favelas conta com poucos exemplos bem sucedidos. Barbo \& Shimbo (2006) mencionam que na política habitacional, até a década de 1990, a concepção de déficit habitacional considerava a necessidade da remoção total das habitações existentes nas favelas e realocação em outras áreas das cidades, em geral distantes do local original.

Observando algumas informações importantes sobre a habitação, Cidades (2010) informa que esta responde por importante parte das necessidades básicas do homem, sendo reconhecida em 1948 pela Declaração dos Direitos Humanos, da Organização das Nações Unidas (ONU), como direito de todo ser humano. No Brasil, a Emenda Constitucional número 26/2000, em seu artigo 6ำ afirma ser um dever do Estado assegurar esse direito.

Santos (2010) menciona que uma das soluções encontradas pela população segregada para manter-se perto de seu ambiente de trabalho foi a construção de assentamentos precários em áreas ambientalmente instáveis a exemplo das encostas de morros (majoritariamente no Rio de Janeiro) e fundos de vales (principalmente na cidade de São Paulo). Assim, Farias (2009) complementa que o adensamento populacional nas grandes cidades alcança níveis muito elevados não apenas pela população presente na cidade formal, mas também com os assentamentos informais presentes em seus arredores.

Entretanto, não é possível desconsiderar que a questão dos assentamentos precários no Brasil é um problema crescente ao longo de toda a história nacional. Piquet (2000) compilou algumas informações referentes a esta questão no Grande Rio e a Tabela 01 - Assentamentos Precários na Região Metropolitana do Rio de Janeiro no Ano 2000. 
Tabela 01: Assentamentos Precários na Região Metropolitana do Rio de Janeiro no Ano 2000

\begin{tabular}{|c|c|c|c|c|c|c|}
\hline Regiāo & $\begin{array}{l}\text { Nome do } \\
\text { municipio }\end{array}$ & $\begin{array}{l}\text { Domicilios } \\
\text { em Setores } \\
\text { Subnormais } \\
\text { (A) }\end{array}$ & $\begin{array}{l}\text { Domicilios } \\
\text { em Setores } \\
\text { Precários } \\
\text { (B) }\end{array}$ & $\begin{array}{c}\text { Estimativa de } \\
\text { Domicilios em } \\
\text { Assentamentos } \\
\text { Precários } \\
\text { (A+B) }\end{array}$ & $\begin{array}{c}\text { Total de } \\
\text { Domicilios } \\
\text { em todos os } \\
\text { Tipos de } \\
\text { Setores }\end{array}$ & $\begin{array}{c}\text { \% de } \\
\text { Domicilios em } \\
\text { Assentamentos } \\
\text { Precários }\end{array}$ \\
\hline \multirow{18}{*}{$\begin{array}{l}\text { RM do } \\
\text { Río de Janeiro }\end{array}$} & Belford Roxo & 541 & 30.167 & 30.708 & 121.619 & 25,25 \\
\hline & $\begin{array}{l}\text { Duque de } \\
\text { Caxias }\end{array}$ & 16.037 & 29.649 & 45.686 & 219.071 & 20,85 \\
\hline & Guapimirim & 0 & 2.125 & 2.125 & 9.230 & 23,02 \\
\hline & Itaboraí & 0 & 3.922 & 3.922 & 50.471 & 7,77 \\
\hline & Itaguaí & 786 & 5.561 & 6.347 & 21.923 & 28,95 \\
\hline & Japeri & 14 & 6.726 & 6.740 & 22.987 & 29,32 \\
\hline & Magé & 4.708 & 7.280 & 11.988 & 55.358 & 21,66 \\
\hline & Nilópolis & 438 & 670 & 1.108 & 44.428 & 2,49 \\
\hline & Niterói & 14.173 & 7.298 & 21.471 & 143.924 & 14,92 \\
\hline & Nova Iguaçu & 1.612 & 40.099 & 41.711 & 260.653 & 16,00 \\
\hline & Paracambi & 128 & 1.030 & 1.158 & 10.597 & 10,93 \\
\hline & Queimados & 319 & 8.279 & 8.598 & 33.334 & 25,79 \\
\hline & Rio de Janeiro & 306.609 & 85.796 & 392.405 & 1.801 .315 & 21,78 \\
\hline & Săo Gonçalo & 58 & 30.149 & 30.207 & 262.890 & 11,49 \\
\hline & $\begin{array}{l}\text { Saso Jošo } \\
\text { de Meriti }\end{array}$ & 3.293 & 15.451 & 18.744 & 129.390 & 14,49 \\
\hline & Seropédica & 0 & 4.839 & 4.839 & 16.972 & 28,51 \\
\hline & Tanguá & 0 & 2773 & 2.773 & 6.321 & 43,87 \\
\hline & Total da RM & 348.716 & 281.814 & 630.530 & 3.210 .483 & 19,64 \\
\hline
\end{tabular}

Fonte: Piquet (2000) a partir de dados do Censo IBGE 2000.

O movimento de resistência à remoção dos assentamentos precários e a luta pelo direito a moradia trouxeram um novo entendimento para a política habitacional brasileira. Dentro deste contexto, em 1995, a Fundação João Pinheiro desenvolveu um estudo propondo um novo conceito de necessidades habitacionais, onde é considerada a inadequação das moradias em assentamentos precários (FPJ, 2014). A inadequação do conceito reflete problemas na qualidade das moradias, contemplando a melhoria nas habitações existentes sem que uma nova construção se faça necessária. A melhoria em habitações precárias existentes visa uma complementação à ação de construção de novas unidades a fim de contribuir para a mitigação do déficit habitacional. 
Durante muitos anos o Estado justificou sua não intervenção em assentamentos localizados em áreas não legalizadas, aumentando a gravidade do problema. A política de remoção de favelas para áreas urbanizadas e, de um modo geral, distantes do local origem, mostrou-se ineficiente. IBGE (2010) menciona que, devido aos 12,4 milhões de pessoas vivendo em assentamentos subnormais, carentes de infraestrutura e em domicílios de construção precária, a urbanização das favelas, incluindo a intervenção na unidade habitacional, passa a representar uma solução para o problema.

\section{2- INICIATIVAS PARA MELHORIA DA QUALIDADE HABITACIONAL}

Apesar da problemática em questão ser um problema grave no Brasil, há de se considerar que muitas iniciativas estão sendo realizadas para a reversão do quadro atual. Primeiramente, acredita-se aqui que a solução da questão habitacional brasileira não está centrada apenas em sanar o déficit habitacional, mas em proporcionar a população em geral boas condições de habitabilidade.

Neste ponto, Rodrigues (1988) já mencionava que o Estado e a Academia não são os únicos detentores dos modos de produção habitacional e, neste ponto, convocar a população para auxiliar nesta questão não é uma necessidade mas sim uma atitude consciente de que a sociedade deve estar presente no provimento de habitações. Conforme a autora menciona, no final dos anos 1980, o município de São Paulo (SP) é o primeiro a apresentar um programa de orientação e suprimento de material às populações de baixa renda para a construção de moradias em um processo conhecido como mutirão habitacional.

Araújo (2010) menciona que a execução de obras e serviços estéticos não são os únicos elementos integradores entre a informalidade dos assentamentos precários à cidade formal, bem como o provimento de infraestrutura a estas novas áreas não é o único ponto de integração. Ao mencionar a política de transportes urbanos, Vasconcellos (2012) afirma que a construção de vias não é suficiente para suplantar a demanda local se esta não for acompanhada de serviços (linhas de desejo) que atendam corretamente os anseios locais de deslocamento. 
Desta maneira, ao receber obras de infraestrutura nos espaços públicos das áreas onde estão os aglomerados subnormais, deve-se ter em vista também o implemento das condições de cada habitação individualmente.

Como um modelo de padronização e indicação de requisitos mínimos para a aplicação de obras nas habitações (de forma geral), ABNT lançou em julho de 2013 a NBR 15.575 que estabelece as condições para o bom desempenho das edificações, com parâmetros objetivos para novas construções. Estes visam à melhoria da qualidade da construção, atendendo às necessidades do usuário e cumprindo uma série de requisitos no desempenho da edificação.

A proposta dessa pesquisa está pautada na apresentaçãs de condições para melhoria das condições de habitabilidade nos domicílios precários com a aplicação dos requisitos técnicos básicos da NBR 15.575, através da autoconstrução supervisionada, na tentativa da inserção dessas comunidades à cidade propriamente dita, proporcionando uma moradia digna a seus habitantes.

Dentre os requisitos da NBR 15.575 estão aqueles exigidos pelo Código Sanitário do Estado de São Paulo, onde os princípios básicos de higiene e saúde devem ser observados. A obediência aos princípios de salubridade prevê dentre outros itens: ventilação e iluminação eficientes, dimensionamento de vãos de janelas e portas, estanqueidade das coberturas e recolhimento de lixo.

Neste ponto, Arruda (2007) indica que além da construção em regimes de mutirão e a melhoria (ou instalação nos casos de ausência) da infraestrutura urbana, muitos estados e municípios tem investido de forma pesada na capacitação de indivíduos no intuito de Ihes proporcionar conhecimento técnico em macro ou micro escala para que, ao realizar obras em seus domicílios, estas venham atender os padrões mínimos e objetivos de desempenho da edificação, tal como mencionado na NBR 15.575.

Dentre estes programas, podem-se destacar duas iniciativas: a primeira, presente no estado de São Paulo onde a Fundação Paula Souza, responsável pelas FATECs e ETECs, ministra cursos de formação profissional técnica e tecnológica na área de construção civil direcionada a formar novos profissionais para o mercado de construção civil em todo estado, enquanto o segundo refere-se a FAETEC do estado do Rio de Janeiro que ministra cursos de capacitação ao público geral, além dos 
cursos regulares de formação técnica e tecnológica (ensino médio), em construção civil. Neste segundo caso, por observação da autora, percebe-se que muitos alunos buscam estes cursos para poder, principalmente, melhorar o desempenho de suas próprias residências ao invés de utilizá-los frente a uma demanda de mercado.

\section{3- CONCLUSÕES INICIAIS}

Existe uma grande lacuna entre produção e demanda de moradias para a população de baixa renda. Os assentamentos informais proliferam sem qualquer financiamento e em situações incabíveis de precariedade. Entretanto, conforme observado, algumas iniciativas tem contribuído para que estas áreas não estejam tão desprovidas de condições básicas para a vivência no ambiente urbano.

A capacitação da mão de obra local visando um aceitável desempenho no processo de autoconstrução fornece aos moradores possibilidades de inserção no mercado de trabalho com qualificação profissional. De acordo com Vidal (2008), a produção habitacional não-tradicional (distinta da construção de conjuntos habitacionais e condomínios residenciais pelo poder público) constitui uma alternativa viável para alguns casos de construir bairros equilibrados para a população com menor poder aquisitivo.

Gouvêa (2005) acredita que dentre os sistemas urbanos presentes nas cidades, aquele destinado as habitações é um dos principais responsáveis pela determinação do adensamento e forma urbana pois a maior parte das construções presentes neste ambiente é destinada ao provimento de residências a população residente.

Desta maneira, Melhado (2013) confirma a afirmação e a expande ao mencionar que a formação de novas áreas urbanas sustentáveis deve priorizar as construções destinadas ao provimento habitacional em primeira medida, conjugada a proximidade dos locais de trabalho e geração de renda, permitindo a ocupação equilibrada do solo e a distribuição balanceada dos recursos disponíveis a toda população.

Este trabalho pretende ser o início de uma contribuição para a melhoria das habitações subnormais a baixo custo cumprindo requisitos básicos de técnica e conforto ambiental. 


\section{REFERÊNCIAS}

ABNT (Associação Brasileira de Normas Técnicas). Norma Brasileira 15.575: Desempenho das Edificações Habitacionais. Rio de Janeiro: Editora ABNT, 2013.

ARRUDA, Ângelo Marcos (Org). Assistência Técnica, um Direito de Todos - Construindo uma Política Nacional: Experiências em Habitação de Interesse Social no Brasil. Brasília: Imprensa Nacional, 2007.

ARAÚJO, Ana Filipa. O Papel do Arquiteto como Mediador entre a Cidade Formal e a Cidade Informal. Lisboa (Portugal): Editora da Universidade de Lisboa, 2010.

BARBO, André \& SHIMBO, loshiaqui. Uma Reflexão Sobre o Padrão Mínimo de Moradia Digna no Meio Urbano Brasileiro. Rio de Janeiro: Revista Estudos Urbanos e Regionais (RBEUR), Número 02/2006.

CIDADES (Ministério das Cidades). Ações Integradas de Urbanização de Assentamentos Precários. Brasília: Imprensa Nacional, 2010.

FARIAS, Jacira. A Forma da Informalidade: uma Análise da Morfologia Urbana da Rocinha. Rio de Janeiro: Editora UFRJ, 2009.

FPJ (FUNDAÇÃO JOÃO PINHEIRO). Déficit Habitacional no Brasil: Resultados Preliminares 20112012. Belo Horizonte: Editora CEI/FPJ, 2014.

GOUVÊA, Ronaldo. A Questão Metropolitana no Brasil. Rio de Janeiro: Editora FGV, 2005.

IBGE (Instituto Brasileiro de Geografia e Estatística). Censo Demográfico 2010: Aglomerados Subnormais, Informações Territoriais. Brasília: Editora IBGE, 2010.

MARQUES, Eduardo (Org). Assentamentos Precários no Brasil Urbano. Brasília: Imprensa Nacional, 2007.

MELHADO, Ana (Org). Projetar e Construir Bairros Sustentáveis. São Paulo: Editora Pini, 2013.

PIQUET, Rosane (Org). Rio de Janeiro: Perfis de uma Metrópole em Mutação. Rio de Janeiro: Editora UFRJ, 2000.

RODRIGUES, Arlete. Moradia nas Cidades Grandes. São Paulo: Editora Contexto, 1988.

SANTOS, Milton. A Urbanização Desigual. São Paulo: EdUSP (3ª edição), 2010.

VASCONCELLOS, Eduardo. Mobilidade Urbana e Cidadania. Rio de Janeiro: Editora SENAC Nacional, 2012.

VIDAL, Fernando. A Autoconstrução e o Mutirão Assistidos como Alternativas para a Produção de Habitações de Interesse Social. Brasília: Editora UnB, 2008. 